\title{
Total laparoscopic hysterectomy: why surgeon teachers must learn and train residents
}

\author{
Shalini Mahana Valecha, Pandeeswari*, Dolly Bashani, Saman Syed
}

Department of Obstetrics and Gynecology, ESI-PGIMSR, Mumbai, Maharashtra, India

Received: 11 December 2018

Accepted: 30 January 2019

\section{*Correspondence:}

Dr. Pandeeswari,

E-mail: pandeeswaribalakrishnan@gmail.com

Copyright: () the author(s), publisher and licensee Medip Academy. This is an open-access article distributed under the terms of the Creative Commons Attribution Non-Commercial License, which permits unrestricted non-commercial use, distribution, and reproduction in any medium, provided the original work is properly cited.

\begin{abstract}
Background: The purpose of the present study is to demonstrate the feasibility of laparoscopic surgery for hysterectomy and elaborate our experience.

Methods: Between September 2017 and April 2018, 15 patients who were counselled for and opted for total laparoscopic hysterectomy our hospital enrolled in this study. Surgeons used a four-port system with, one $10 \mathrm{~mm}$ and three 5-mm trocars. All surgical procedures were performed with $30^{\circ}$, 10-mm laparoscope and conventional laparoscopic instruments including monopolar and bipolar cautery system and the LigaSure system. Patient's history, clinical findings and surgical outcomes were prospectively tabulated, evaluated and analyzed.

Results: Out of 15 patients under the study with age range of 40-55years, only 2 patients had hypertension and diabetes mellitus and 2 had anaemia. All 15 patients underwent conventional laparoscopic surgery. Operative time was in a range of 60-240 min. There were no intra operative complications in 6 patients (40\%) and no post op complications in 11 women $(73 \%)$.

Conclusions: The results from our 15 women show that, in experienced hands, laparoscopic hysterectomy is not associated with any increase in major complication rates.
\end{abstract}

Keywords: Coagulation, Hysterectomy, Laparoscopy

\section{INTRODUCTION}

The first total laparoscopic hysterectomy (TLH) was performed by Reich et al. in 1989. Since then, several authors have reported their experience with this operation thus demonstrating that it can be reproduced. TLH is currently accepted as a feasible and safe way for the treatment of benign uterine pathology as an acceptable alternative to standard abdominal hysterectomy.

However, most studies set arbitrarily as a limit of uterine size the equivalent of 14 weeks of gestation to make a uterus suitable for laparoscopic surgery. ${ }^{1}$ A relative contraindication to laparoscopy is obesity, because it presents a major difficulty in establishing pneumoperitoneum and anaesthesiological difficulties with the Trendelenburg position in these women. The majority of authors define obesity as a BMI > $30 \mathrm{~kg} / \mathrm{m}^{2}$ and the Gynecologic Oncology Group (GOG) limits laparoscopic surgery to women with BMI $<35 \mathrm{~kg} / \mathrm{m}^{2}$.

Indeed, it has been reported that in these cases there is an increased chance of conversion to laparotomy whereas the morbidity and hospital stay were similar between lean and obese patients. ${ }^{2}$

Total laparoscopic hysterectomy is the removal of uterus and cervix through four small abdominal incisions. Removal of ovaries and tubes depends on the patient. Number of provider barriers had been identified, 
including insufficient experience and training and lack of hospital equipment. It is safe and effective procedure for women needing a hysterectomy. ${ }^{3}$ Surgical advantages to laparoscopy are related to the magnification provided in the pelvis, facilitating access to the uterine vessels, ureter, rectum and vagina. Patient advantages are also multiple and are related to avoidance of painful abdominal incision. They include shorter hospital stay, early recovery and low rate of infection. ${ }^{4}$

TLH is an advanced gynaecological laparoscopy procedure requiring good understanding of pelvic anatomy, efficiency in the safe use of energy sources, as well as laparoscopic suturing and knotting skills. Robotic TLH is being performed in some centres where the facilities are available, but this has not demonstrated any advantage over the non-robotic approach. ${ }^{5}$

There are many benefits of laparoscopy over open mode of surgery like no large incision in the abdomen and minimal blood loss during surgery. There is low risk of infection and developing adhesions. Bowel function returns to normal more quickly, less pain medication required after surgery with expedient post-op recovery hospital stay is shortened making the procedure costeffective for the patient and health care organization.

Some intra operative complications that authors came across during surgeries are bleeding, adhesions, scarring, large uterus and some anaesthesia related complications. In post-operative period, patients had occasionally minor complaints like nausea, vomiting, shoulder pain, pain in abdomen, bloating sensation and in one case leaking per vaginum.

Minor complications seen in present study included gastritis, mild fever which subsided by intravenous antibiotics and anti pyretics while major included conversion to laparotomy (due to vessel injury), haemorrhage resulting in post op anemia requiring blood transfusion and repair of urinary tract injuries.

Thus, in selected patients, the laparoscopic approach to hysterectomy may avoid the increased morbidity associated with abdominal surgery while retaining the surgical advantages of the abdominal approach i.e. thorough visualization and easy access to the vascular pedicles.

\section{METHODS}

Between September 2017 and April 2018, 15 patients who initially planned to total laparoscopic hysterectomy in our hospital enrolled in this study.

Hysterectomies were performed in case of AUB not responding to medical therapy, AUB with simple endometrial hyperplasia, Adenomyosis, Postmenopausal with simple endometrial hyperplasia, UV descent, Uterine fibroid.

\section{Exclusion criteria}

- Hysterectomy for malignant disease, such as endometrial cancer, cervical cancer and ovarian cancer.

All the operations were performed by same team using the same reproducible techniques. A total of 3 consultant surgeon, assisted by residents in training, performed these procedures.

During the surgery, all complications were recorded. Any remarkable events occurring in the course of the operation, as well as immediate postoperative were noted in hospital Database. All women reviewed there after weekly for 6 weeks. Data on all surgical procedures were subsequently collected from hospital Database.

They were reviewed in detail, peri-operative complications, correction and follow-up were note. Postoperative outcomes were also summarised from the medical file. Immediate post-operative adverse events were recorded, as were following up until complete resolution of the complications.

\section{RESULTS}

Out of 15 patients in present study $8(53.33 \%)$ patients were aged between 40-45years, $5(33.33 \%)$ patients were aged between $46-50$ years, $2(13.33 \%$ ) patients were aged between 51-55 years (Figure 1).

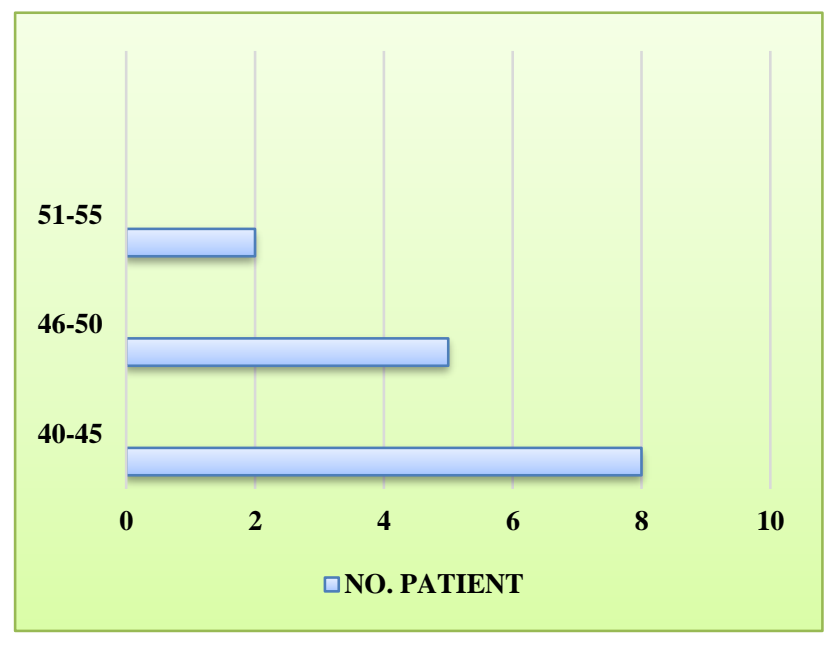

Figure 1: Age of the patients.

In present study out of 15 patients, $4(26.6 \%)$ patients were operated for AUB not responding to medical therapy, $3(20 \%)$ patients were operated for AUB with endometrial hyperplasia, $3(20 \%)$ patients were operated for Adenomyosis, 1 (6.6\%) patient was operated for postmenopausal with simple endometrial hyperplasia, $2(13.3 \%)$ patients were operated for UV descent, 2 $(13.3 \%)$ patients were operated for uterine fibroid (Table 1). 
Table 1: Indications of surgery.

\begin{tabular}{|l|l|l|}
\hline Indications & Total & $\%$ \\
\hline AUB not responding to medical therapy & 4 & 26.6 \\
\hline AUB with simple endometrial hyperplasic & 3 & 20 \\
\hline $\begin{array}{l}\text { Adenomyosis } \\
\text { Postmenopausal with simple endometrial } \\
\text { hyperplasia }\end{array}$ & 3 & 20 \\
\hline UV descent & 1 & 6.6 \\
\hline Uterine fibroid & 2 & 13.3 \\
\hline Total & 2 & 13.3 \\
\hline
\end{tabular}

In present study out of 15 patients $2(13.3 \%)$ patients had diabetics and hypertension, $1(6.6 \%)$ patient had diabetes only, one $(6.6 \%)$ patient had hypertension only, $2(6.6 \%)$ patients had anaemia, one (6.6\%) patient had obesity, one $(6.6 \%)$ patient had tuberculosis, no preoperative risk factors noted in 7 (46.6\%) patients (Figure 2).

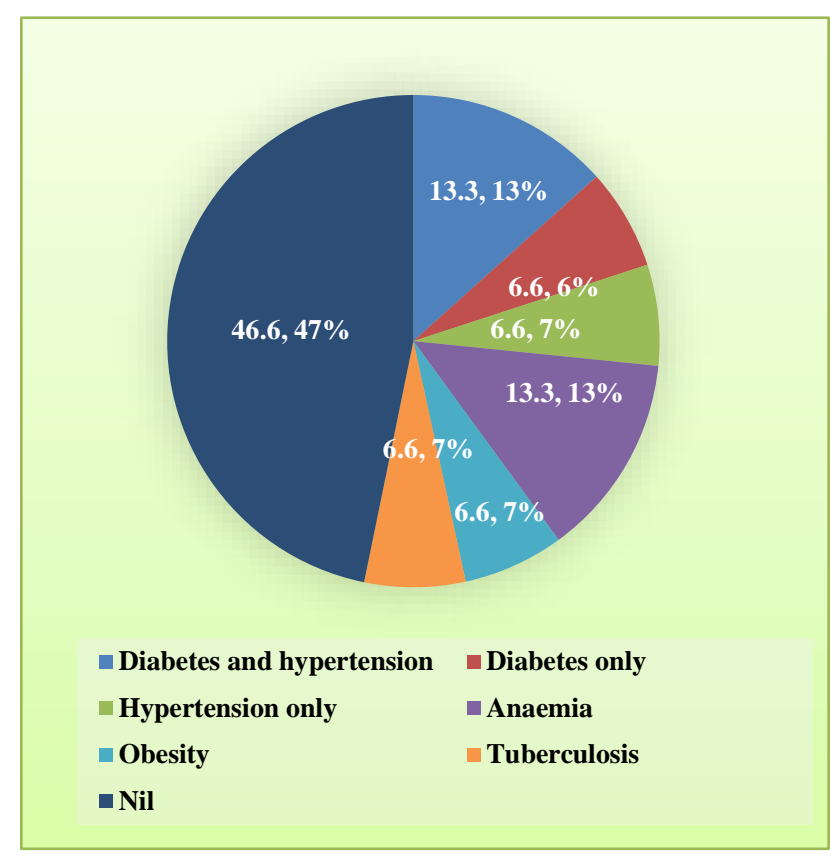

Figure 2: Preop risk factors.

After getting fitness from anaesthetist patients were posted for surgery.

These preoperative co morbidities affect the outcomes after surgery and produce significant impact on complications.

In present study out of 15 patients, excluding the anaesthesia induction time and extubation time, 2 $(13.3 \%)$ patients operated in the range of 60-120 $\mathrm{min}, 7$ $(46.6 \%)$ patients operated in the range of $120-180 \mathrm{~min}, 6$ (40\%) patients operated in the range of 180-240 min. duration of surgery depends on the operating surgeon skills, availability of instruments, and skilful assistants, patient selection criteria (Figure 3).

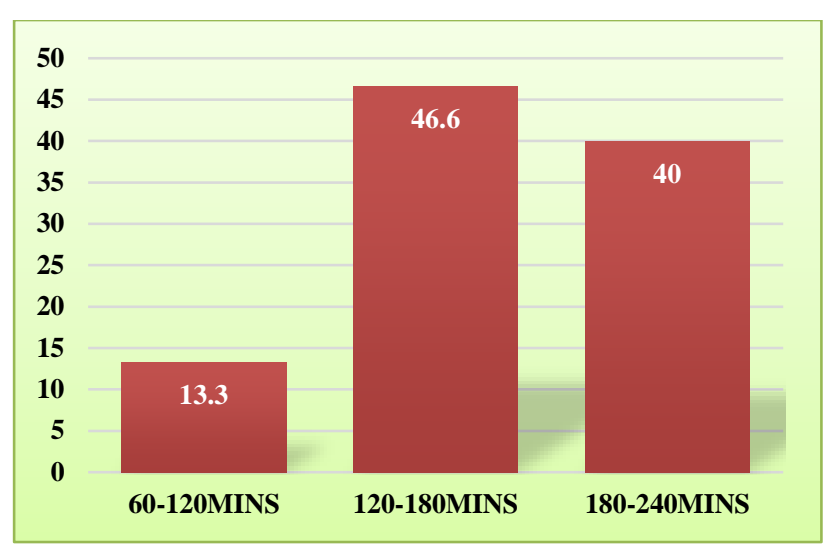

Figure 3: Duration of surgery.

In a comparative study between LAVH and TLH, Roy et al. suggested that TLH required a significantly longer operative time, but it resulted in less blood loss.

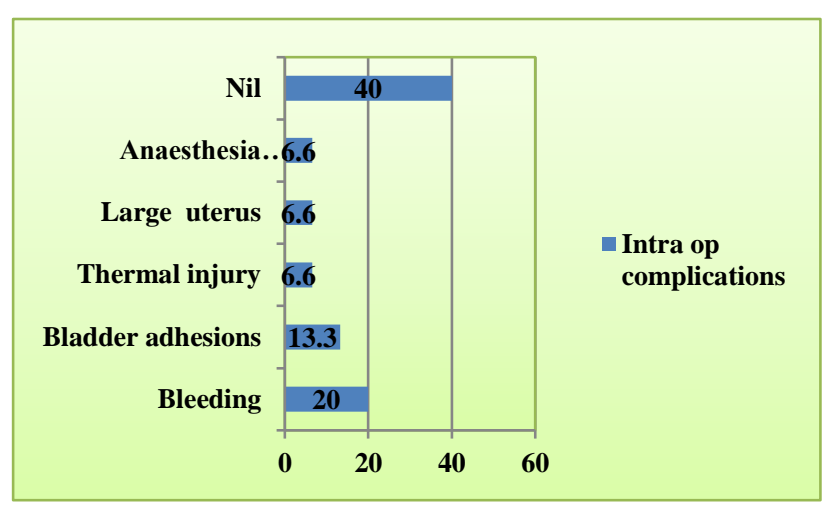

Figure 4: Intra OP complications.

In present study, during the procedure, $3(20 \%)$ patients developed bleeding, $2(13.33 \%)$ patients found to have bladder adhesions, one (6.6\%) patient had large uterus, one $(6.6 \%)$ patient developed thermal injuries, one (6.6\%) patient developed anaesthesia complications, no intra-op complications in 6 (40\%) patients (Figure 4).

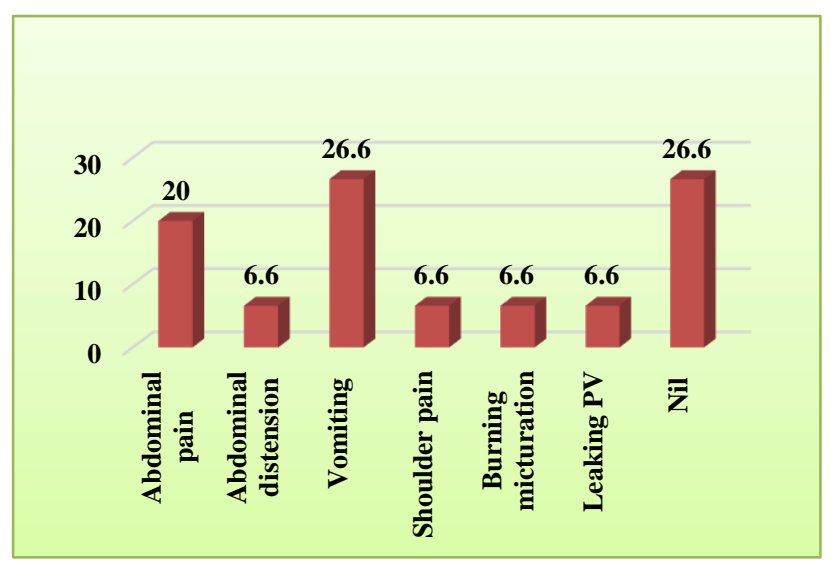

Figure 5: Postoperative complaints. 
In Ingole et al study, they found four cases of bladder injury for which laparoscopic surgery was abandoned and hysterectomy with subsequent bladder repair was completed by opening the abdomen. Out of four cases of bladder injury, one patient had history of previous cesarean section. ${ }^{15}$ Two patients had dense adhesions and hence were converted to open surgery before any significant laparoscopic dissection was done. In present study out of 15 patients, $3(20 \%)$ developed abdomen pain, one $(6.6 \%)$ patient developed abdomen distension, 4 (26.6\%) patients developed vomiting, one $(6.6 \%)$ patient had shoulder pain in the post-operative period, one $(6.6 \%)$ patient had burning micturation, one $(6.6 \%)$ patient had leaking per vagina, no complaints from 4 patients (Figure 5). These complaints were less as compared to other modalities of hysterectomy. In present study, out of 15 patients, 3 (20\%) patients developed anaemia in the remote postoperative period, one $(6.6 \%)$ patient developed gastritis, one $(6.6 \%)$ patient developed UV fistula (Figure 6). This patient was presented in our hospital on day 6 of postoperative day with leaking per vaginum, advised for CT Urography and diagnosed to have UV fistula. Afterwards she underwent stending procedure and recovered with stenting procedure itself. No postoperative complications noted in 11 (73.3\%) patients.

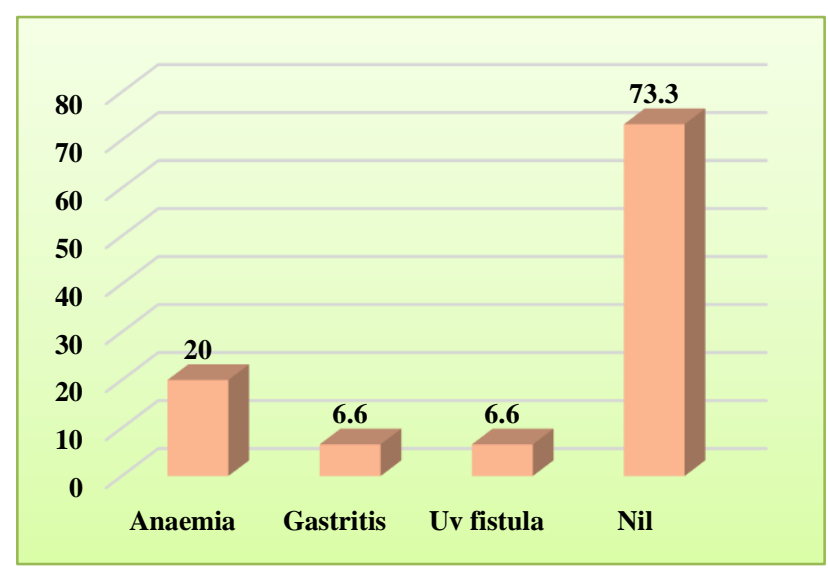

Figure 6: Postoperative complications.

\section{DISCUSSION}

TLH can represent an optimal way to avoid laparotomy when the conditions are against the vaginal approach as in cases of large uterus or those out of proportion to the vagina. In such cases it is necessary to turn to ancillary techniques to reduce the uterine volume such as morcellation, hemi-section, enucleation of myomas, or intra-myometrial coring. Therefore, it has been suggested to approach large uteri in nulliparous patients through an abdominal route, namely laparotomy.

Local adaptation and clever improvisation are highly essential to the successful practice of gynecological laparoscopy in a resource-poor setting. For instance, the use of advanced energy sources such as Harmonic $₫$ and
LigaSure ${ }^{\circledR}$ is widespread for TLH, but these technologies are not readily available in resource-poor settings. In present study, the case presented, the entire procedure was successfully carried out using simple monopolar or bipolar diathermy and in some with Ligasure.

The safety of day-case TLH is well-established. Most of our patients were discharged home on the third to fourth post-operative day in stable condition. The possibility of such early discharge is an important advantage in a public health care facility like ours where there is usually a lot of pressure on bed spaces owing to a large turnover of patients for gynecological surgery and a limited number of beds. ${ }^{5}$ If the uterus is large and requires manipulation with a tenaculum, consider injecting dilute vasopressin sub-serially prior to applying traction to the uterus. This can reduce bleeding associated with pulling and tearing of the uterine serosa.

If access to the uterine vessels is difficult, take the uterine vessels up high initially to secure the blood supply to the upper uterus and then gradually work down, staying medial to the vessels. Step-wise devascularization by cauterizing multiple pedicles is helpful. Reduced bleeding improves visibility and expedites the procedure. Simple use of suction-irrigation at frequent intervals keeps the field blood-free.

The combination of a prior caesarean delivery or any other abdominal injury leading to adhesions and a large uterus is a set up for bladder injury. So, it is advisable to stay high on the vesico-uterine peritoneum, respect any fat that is seen and always watch out for presence of ureters in our surgical field.

All attempts to keep the intestine out of the pelvis must be made. Pre-op bowel preparation with liquid diet and laxatives and adequate NBM is advised. Steep Trendelenburg and hand instruments designed to keep bowels are out of field. As far as surgical time is concerned, various factors like indication for surgery, patient's BMI, availability of advanced electrosurgical hand instruments, surgeon experience and expertise even expert assistance all come into play. Improvement with time is the norm and achievable by most surgeon.

In severely distorted anatomy consider entering the retroperitoneum sooner rather than later. The easiest starting point is usually at the round ligament. ${ }^{6}$

Dysfunctional uterine bleeding and uterine fibroids comprised $83 \%$ and $77 \%$ of primary indications for surgery, respectively. Wattiez et al study revealed out of 1647 Cases excessive hemorrhages (1.9\%) and need for blood transfusion $(2.2 \%)$. Urinary complications $(2.2 \%)$ including 10 bladder lacerations, 4 ureter injuries, and 1 vesicovaginal fistula. One bowel injury and one bowel obstruction occurred in the first period, but no bowel complications in the second. Three diagnostic laparoscopies were required due to postoperative 
abdominal pain. ${ }^{7}$ Bojahr et al found $0.23 \%$ of urinary tract injury rate in a series of 1706 laparoscopic hysterectomies. $^{7}$ Karaman et al obtained major complications rate $1 \%$ with no injury to urinary tract structures. $^{8}$ Ali Ghomi, et al they found 2 complications in their series; the first patient had undergone an LSH for a symptomatic fibroid uterus. She underwent a reexploratory laparotomy and was found to have a delayed thermal injury to the sigmoid colon, which required a segmental resection and colostomy. The second case was a conversion to laparotomy due to incidental cystotomy. The patient had 2 prior Cesarean deliveries and underwent an LSH for menorrhagia. Incidental cystotomy was encountered during sharp bladder dissection. A decision was made to convert the case to laparotomy for cystotomy repair. The cystotomy was repaired in 2 layers by using delayed absorbable sutures. The supracervical hysterectomy was completed via laparotomy. The patient was discharged on postoperative day 3 with an indwelling transurethral catheter. $^{9}$ Liu and Reich reviewed 518 patients undergoing TLH. They found that the risk of TLH is no greater than either abdominal hysterectomy or vaginal hysterectomy in appropriately trained hands. ${ }^{10}$ Patients with TLH experience less pain and require less postoperative analgesia as compared to Abdominal Hysterectomy. Though some studies have mentioned longer operating time and longer anaesthesia, TLH is associated with shorter stay and early recovery from the surgery as compared to $\mathrm{AH} .^{11}$

Mani et al concluded that, there are many good indications of TLH in patients with previous abdominal surgery, multiple fibroids, limited vaginal access, nulliparity or broad ligament myoma. In other indications LAVH should be considered a better option because of less operative time and reduced cost of surgery. Total Laparoscopic hysterectomy has a genuine concern of ureteric injury. ${ }^{12}$ In a Gendy metaanalysis comparing VH and TLH, TLH was associated with shorter hospital stay, with no differences in complications, blood loss or urinary tract injury. ${ }^{13}$ Sonali Ingole concluded that, TLH is safe and effective procedure for most of the benign pelvic conditions. With adequate training TLH can be used more widely in tertiary care hospital and teaching institute. $^{14,15}$

\section{CONCLUSION}

Authors operated and studied a series of cases with benign gynaecological pathology undergoing TLH and tabulated our finding. Compare to other modes of hysterectomy in laparoscopy small incision in the abdomen, less blood loss during surgery, low risk of infection, minimal risk of developing adhesions, early return of gastrointestinal function, less hospital stay, patients can start routine work in short time. During laparoscopy surgery the surgeon will also look at other organs such as the liver, spleen, stomach, intestines, peritoneum for pathology. Extreme caution is advised while handling electrosurgical hand instruments. In our experience use of vessel sealers reduces bleeding, damage to surrounding structures and due to vastly improved cauterization and cutting function decreases operative time, and intra/post-op complications. In our series the one case which developed UV fistula had been operated using bipolar cautery and monopolar scissors. Lateral spread of current and heat injury are a worrisome concern, but through knowledge and careful deployment can minimise risk.

In experienced hands laparoscopic hysterectomy is a safe, cost-effective and beneficial technique for both the patient and the surgeon. Expertise in laparoscopic procedures and adherence to the safety rules are nevertheless paramount to avoid any serious complications that may occur. Abdominal, vaginal and laparoscopic procedures all have their own indications and need to be performed with the same level of applications and skill. Though vaginal approach should be given its due place, patients are opting for laparoscopic approach and it is well worth the effort to learn and perfect this procedure. Surgeons from the teaching faculties must make a specific effort to learn and teach these operations to residents in order to make them future ready. No resident training programme can be considered comprehensive without exposure to laparoscopic hysterectomy as surgical option.

Funding: No funding sources Conflict of interest: None declared

Ethical approval: The study was approved by the Institutional Ethics Committee

\section{REFERENCES}

1. Chapron C, Dubuisson JB, Aubert V, Morice P, Garnier P, Aubriot FX, Foulot H. Surgery: Total laparocscopic hysterectomy: preliminary results. Human Reproduct. 1994;9(11):2084-9.

2. Eltabbakh GH, Piver MS, Hempling RE, Recio FO. Laparoscopic surgery in obese women. Obstet Gynecol. 1999;94(5 pt 1):704-8.

3. Laurie , crimando RNC,MSN REVIEWERS K., Wang, MD INFORMATIONAND /OR instructional materials developed by University of Michigan Health System Last. Available at https://www.med.umich.edu/1libr/Gyn/SCH.pdf

4. Donnez O, Jadoul P, Squifflet J, Donnez J. A series of 3190 laparoscopic hysterectomies for benign disease from 1990 to 2006: evaluation of complications compared with vaginal and abdominal procedures. BJOG: Int J Obstet Gynaecol. 2009;116(4):492-500.

5. Olusegun OB, Kayode OA, Babawale OO, and Adebanjo BA. Total laparoscopic hysterectomy: A case report from ILE-IFE, Nigeria Niger Med J. 2012;53(4):254-6. 
6. Einarsson JI, Suzuki Y. Total laparoscopic hysterectomy: 10 steps toward a successful procedure. Rev Obstet Gynecol. 2009;2(1):57.

7. Wattiez A, Soriano D, Cohen SB, Nervo P, Canis M, Botchorishvili R, Mage G, Poul JL, Mille P, Bruhat MA. The learning curve of total laparoscopic hysterectomy: comparative analysis of 1647 cases. The Journal of the American Association of Gynecologic Laparoscopi. 2002;9(3):339-45.

8. Bojahr B, Raatz D, Schonleber G, Abri C, Ohlinger R. Perioperative complication rate in 1706 patients after a standardized laparoscopic supracervical hysterectomy technique. J Minimal Invas Gynecol. 2006;13(3):183-9.

9. Ghomi A, Littman P, Prasad A, Einarsson JI. Assessing the learning curve for laparoscopic supracervical hysterectomy. JSLS: Journal of the Society of Laparoendoscopic Surgeons. 2007;11(2):190.

10. Liu CY. Complications of total laparoscopic hysterectomy in 518 cases. Gynaecol Endosc. 1994;3:203-8.

11. Garry R. The future of hysterectomy. BJOG: An International Journal of Obstetrics \& Gynaecology. 2005;112(2):133-9.

12. Mani K, Govindarajan M, Selvaraj V. Comparison of total laparoscopic hysterectomy and laparoscopic assisted vaginal hysterectomy:a 2-year retrospective study. Int J Reprod Contracept Obstet Gynecol. 2017;6(3):966-9.

13. Gendy R, Walsh CA, Walsh SR, Karantanis E. Vaginal hysterectomy versus total laparoscopic hysterectomy for benign disease: a metaanalysis of randomized controlled trials. Am J Obstet Gynecol. 2011;204(5):388-90.

14. Roy KK, Goyal M, Singla S, Sharma JB, Malhotra $\mathrm{N}$, Kumar S. A prospective randomised study of total laparoscopic hysterectomy, laparoscopically assisted vaginal hysterectomy and non-descent vaginal hysterectomy for the treatment of benign diseases of the uterus. Arch Gynecol Obstet. 2011;284(4):90712.

15. Ingole S, Darawade S. Trends and patterns in total laparoscopic hysterectomy in tertiary care hospital. Int J Reprod Contracept Obstet Gynecol. 2018;7(6):2170-3.

Cite this article as: Valecha SM, Pandeeswari Bashani D, Syed S. Total laparoscopic hysterectomy: why surgeon teachers must learn and train residents. Int J Reprod Contracept Obstet Gynecol 2019;8:9416. 